\title{
Fatigue assessment by FACIT-F scale in Pakistani cohort with Rheumatoid Arthritis (FAF-RA) study
}

\author{
Abrar Ahmed Wagan', Abdul Raheem², \\ Afra Bhatti ${ }^{3}$, Taimoor Zafar $^{4}$
}

\begin{abstract}
Objective: To fine out fatigue frequency and severity by FACIT-F scale in Pakistani cohort with rheumatoid arthritis.

Methods: This study was conducted at department of Medicine division of rheumatology CPMC Lahore. After the approval of IRB, 192 patients of RA were recruited. Written, informed consent was taken, demographic details were noted, patients filled the URDU version of FACIT-F (fatigue severity scale). 5-ml of blood was taken for fasting blood sugar, viral markers and ESR by a trained phlebotomist. Each individual's disease activity was assessed by DAS-28 and FACIT-F score was calculated.

Results: The Mean age $(39.9 \pm 10.5)$ years, $(71.9 \%)$ were females. Fatigue frequency was $62 \%(n=126)$, age, education, hypertension, DAS-28, exercise levels and HCV gives significant association with fatigue score. Linear regression analysis, results showed one unit increase in DAS-28 will gives 2.71 unit increases in fatigue scores $(\mathrm{P}<0.05)$.

Conclusions: We have very high frequency of fatigue in RA, increases with disease activity \& associated conditions.
\end{abstract}

KEYWORDS: Fatigue, Das-28, RA, FACIT-F score, HCV.

doi: https://doi.org/10.12669/pjms.37.4.3602

How to cite this:

Wagan AA, Raheem A, Bhatti A, Zafar T. Fatigue assessment by FACIT-F scale in Pakistani cohort with Rheumatoid Arthritis (FAFRA) study. Pak J Med Sci. 2021;37(4):1025-1030. doi: https://doi.org/10.12669/pjms.37.4.3602

This is an Open Access article distributed under the terms of the Creative Commons Attribution License (http://creativecommons.org/licenses/by/3.0), which permits unrestricted use, distribution, and reproduction in any medium, provided the original work is properly cited.

\section{INTRODUCTION}

1. Dr. Abrar Ahmed Wagan, MBBS, FCPS (Medicine),

FCPS (Rheumatology), FACR.

Assistant Professor,

Indus Medical College,

Tando Mohammad Khan, Pakistan.

2. Dr. Abdul Raheem, MBBS.

3. Dr. Afra Bhatti, MBBS.

4. Dr. Taimoor Zafar, MBBS.

2-4: Postgraduate Trainee,

Central Park Medical College Lahore,

Lahore, Pakistan.

Correspondence:

Dr. Abrar Ahmed Wagan, MBBS, FCPS (Medicine), FCPS (Rheumatology) FACR

Postal Address: Flat No-5 Hashim Residency-II,

Near Saint Bona venture High School Qasimabad,

Hyderabad, Pakistan.

Postal Code: 71000

Email: bestabrar2002@yahoo.com

* Received for Publication:

* Revision Received:

* Accepted for Publication:
September 4, 2020

October 12, 2020

March 26, 2021
Rheumatoid arthritis is an autoimmune disease prevalent mostly in young to middle-aged women, with hallmark features of synovitis leading to articular cartilage - bone destruction, deformities, osteoporosis, and constitutional features. ${ }^{1}$ Fatigue is perceived as lack of energy, leading to disruption of daily activities and it is widely present in all autoimmune disorders. Fatigue in RA is due to multiple reasons like: Pain, mental stress, depression, disease activity, medications and disability, its severity varies with different times of day. ${ }^{2}$

Unlike normal day to day tiredness, fatigue in RA is chronic, not related to overexertion and it persists even after adequate rest. It's an important physical and cognitive symptom which is difficult to control, very unpredictable, overwhelming, and affects every aspect of life. ${ }^{3}$ In recent Brazilian study 
the frequency of fatigue was estimated around $71.25 \%$ while overall range between $40 \%$ to $80 \%{ }^{4,5}$ Dupond et al, also reported near similar frequency range of $20 \%$ to $70 \%$ and described psychological fatigue or weariness as most common pattern, and depression being the most common cause of fatigue in inflammatory rheumatic diseases. ${ }^{6}$

Minnock et al, did a longitudinal study with RA patients $(n=87)$ to know the correlation of fatigue and disease activity, results revealed fatigue is not explained by disease activity as represented by the ACR core set outcomes, rather it's a behavioral variable with multifactorial influences. ${ }^{7}$

Trine Pilgaard et al, in most recent study of 633 patients with three major autoimmune diseases, RA,ankylosing spondyloarthritis and psoriatic arthritis found fatigue frequency of $61 \%$ and interestingly they used most recent FACIT-F questionnaire for fatigue assessment. ${ }^{8}$

Assessment of fatigue is problematic due to lack of an objective marker, albeit there are more than 12 patient-reported outcome measures (PROMs) such as Profile of Mood States, Short Form 36 (SF-36), Multidimensional Assessment of Fatigue, Ordinal Scales, Visual Analog Scales, and Functional Assessment of Chronic Illness Therapy-Fatigue (FACIT-F). ${ }^{9}$ FACIT-F, invented in 1997, covers physical, functional and emotional fatigue, also assess its social consequences with good internal consistency and reliability. ${ }^{10}$

Worldwide more focus has been given to fatigue and its socio-economic impact; through this study we have tried to assess the fatigue frequency in local population and its association with other conditions.

\section{METHODS}

After the approval of IRB(CPMC/IRB/1723) this cross sectional study was conducted at Central Park Medical College outpatient department of medicine division of rheumatology. Written and informed consent was taken from each participant. A sample size of 192 cases was calculated.

Seropositive (RA factor and anti-CCP antibody) RA patients were included. Sero-negative RA,SLE, Scleroderma, Sjogren syndrome, MCTD, psoriatic arthritis, osteoarthritis, primary or secondary fibromyalgia, polymyalgia rheumatic, physical disability, hypothyroidism, history of chemotherapy or radiotherapy in last two years, use of biological DMARDs, known cases major depression, panic disorders, somatization disorders, injudicious use of following medications (hypnotics, muscle relaxants, antidepressants, firstgeneration antihistamines, beta-blockers, opioids), chronic diseases were excluded.

A questionnaire was used to collect demographic data; it included outcomes such as years since diagnosis, marital status, education, employment status, exercise level, social status and smoking habits. Each participant BMI and Blood pressure was measured as per laid down protocols. Afterward $5 \mathrm{ml}$ of blood was drawn by a trained phlebotomist for CBC, ESR, fasting blood sugar levels, $\mathrm{Hbs} \mathrm{Ag}$ and anti HCV Antibody test. Fatigue assessment we used FACIT-F scale (URDU-version), its permission was sought prior to its use. The FACIT-Fatigue scale is a 13-item questionnaire assessing self-reported fatigue and the total score ranges from 0 to 52. For analysis of severity of fatigue, scores were categorized into four grades: composite score $40-52=$ little or no fatigue, score: $27-39=$ some fatigue, score: $14-$ 26 =quite a lot of fatigue, score: $0-13=$ extreme fatigue. Rheumatoid arthritis disease activity score was calculated by DAS-28 calculator. Each study patient was examined by a senior physician.

Statistical Analysis: Analysis was done by using IBM-SPSS version 23.0. Count with percentages given for qualitative characteristics, Mean with standard deviation given for quantitative characteristics of samples. Pearson Chi Square test was used to check the association of fatigue scores with studied parameters. Pearson Correlation analysis was done to see the relationship of fatigue score with body mass index, SBP, DBP, FBS and DAS. Linear regression analysis was done to design a model to analyze the dependency of fatigue score on SBP, DBP and disease activity score after adjusting for age and BMI, p-values less than 0.05 were considered significant.

\section{RESULTS}

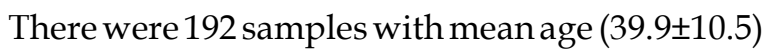
years, $(47.9 \%)$ were aged between $31-45$ years old, $(71.9 \%)$ female gender, $(45.3 \%)$ obese, the mean BMI was $30.1 \pm 6.3 \mathrm{~kg} / \mathrm{m} 2$, (80.7\%)married samples, (25.5\%)secondary and higher educated, (56.8\%) belongs to poor working class, $(35.9 \%)$ middle class, $(76 \%)$ nonsmoker, $(21.4 \%)$ were doing regular exercise, $(60.4 \%)$ never performed exercise, $(33.9 \%)$ samples had DAS-28 under 2.6 defined as disease remission, $(10.4 \%)$ were HCV positive and $(2.6 \%)$ Hbs-Ag positive. Table-I.

The mean disease duration was (6.85 \pm 4.39$)$ years, mean weight was $(80.42 \pm 15.52) \mathrm{kg}$, mean height 
Table-I: Baseline Characteristics of Study Samples $(n=192)$.

\begin{tabular}{|c|c|c|c|}
\hline \multicolumn{2}{|l|}{ Variables } & \multirow{2}{*}{$\frac{n}{44}$} & \multirow{2}{*}{$\frac{\%}{22.9}$} \\
\hline \multirow{4}{*}{$\begin{array}{l}\text { Age } \\
\text { Group } \\
\text { (years) }\end{array}$} & $<=30$ years & & \\
\hline & $31-45$ years & 92 & 47.9 \\
\hline & $>45$ years & 56 & 29.2 \\
\hline & $M e a n \pm S D$ & \multicolumn{2}{|c|}{$39.9 \pm 10.5$} \\
\hline \multirow{2}{*}{ Sex } & Female & 138 & 71.9 \\
\hline & Male & 54 & 28.1 \\
\hline \multirow{4}{*}{$\begin{array}{l}\text { BMI } \\
\text { Levels } \\
\left(\mathrm{kg} / \mathrm{m}^{2}\right)\end{array}$} & $<24.9$ :Normal weight & 39 & 20.3 \\
\hline & 25 - 29.9:over weight & 66 & 34.4 \\
\hline & $>30$ Obese & 87 & 45.3 \\
\hline & Mean $\pm S D$ & \multicolumn{2}{|c|}{$30.1 \pm 6.3$} \\
\hline \multirow{3}{*}{$\begin{array}{l}\text { Marital } \\
\text { Status }\end{array}$} & Married & 155 & 80.7 \\
\hline & Unmarried & 26 & 13.5 \\
\hline & Other & 11 & 5.7 \\
\hline \multirow{4}{*}{$\begin{array}{l}\text { Educa- } \\
\text { tion }\end{array}$} & Uneducated & 78 & 40.6 \\
\hline & Primary & 17 & 8.9 \\
\hline & Secondary and higher & 49 & 25.5 \\
\hline & Bachelors and beyond & 48 & 25.0 \\
\hline \multirow{4}{*}{$\begin{array}{l}\text { Social } \\
\text { Status }\end{array}$} & Upper & 14 & 7.3 \\
\hline & Middle & 69 & 35.9 \\
\hline & Working & 32 & 16.7 \\
\hline & Poor & 77 & 40.1 \\
\hline \multirow{2}{*}{ Smoking } & Smoker & 46 & 24.0 \\
\hline & Nonsmoker & 146 & 76.0 \\
\hline $\begin{array}{l}\text { Hyper- } \\
\text { tension }\end{array}$ & Yes & 37 & 19.3 \\
\hline \multirow{3}{*}{$\begin{array}{l}\text { Exercise } \\
\text { Level }\end{array}$} & Regular & 41 & 21.4 \\
\hline & Never & 116 & 60.4 \\
\hline & Occasional & 35 & 18.2 \\
\hline \multirow{5}{*}{ DAS-28 } & $<2.6$ : Remission & 65 & 33.9 \\
\hline & 2.6-3.2 : Low & 44 & 22.9 \\
\hline & 3.2 - 5.1 : Moderate & 61 & 31.8 \\
\hline & $>5.1$ : High & 22 & 11.5 \\
\hline & Mean $\pm S D$ & \multicolumn{2}{|c|}{$3.4 \pm 1.2$} \\
\hline $\mathrm{HCV}$ & Positive & 20 & 10.4 \\
\hline $\mathrm{Hbs}$ & Positive & 5 & 2.6 \\
\hline
\end{tabular}

Table-II: Baseline Quantitative Parameters.

\begin{tabular}{lcc}
\hline Parameters & Mean & SD \\
\hline Duration of disease & 6.85 & 4.29 \\
Weight (kg) & 80.42 & 15.52 \\
Height (inches) & 64.59 & 3.55 \\
SBP & 121.45 & 17.40 \\
DBP & 79.48 & 9.0 \\
FBS & 104.25 & 29.73 \\
Fatigue score & 34.94 & 8.88 \\
\hline
\end{tabular}

(64.59 \pm 3.55$)$ inches, mean SBP $(121.45 \pm 17.40)$ $\mathrm{mmHg}$, mean DBP $(79.48 \pm 9.0) \mathrm{mmHg}$, mean FBS $(104.25 \pm 29.73) \mathrm{mg} / \mathrm{dl}$, mean DAS-28 score $(3.4 \pm 1.2)$, and mean fatigue scores was $(34.94 \pm 8.88)$ units. Table-II.

Fatigue frequency was $62 \%(n=126)$, some fatigue was present in $45.8 \%(n=88)$, quiet allot of fatigue in $19.3 \%(n=37)$ and extreme fatigue $0.5 \%(n=1)$ Bar Chart-1.

While association of fatigue scores with studied parameters, results showed, age, education, hypertension, DAS-28, exercise levels and HCV gives significant association with fatigue scores levels, whereas there was no significant association obtained for gender, Marital Status, BMI levels, smoking, social status and Hbs. Table-III.

Correlation analysis of fatigue scores with quantitative parameters, results showed body mass index gives $15.1 \%$ negative relationship with fatigue scores, DBP was also $14.8 \%$ negatively associated, and DAS- 28 gives $42.6 \%$ positive association with fatigue scores. These correlations found statistically significant with $(<0.05)$. Table-IV.

Linear regression analysis, results showed one unit increase in DAS-28 will gives 2.71 unit

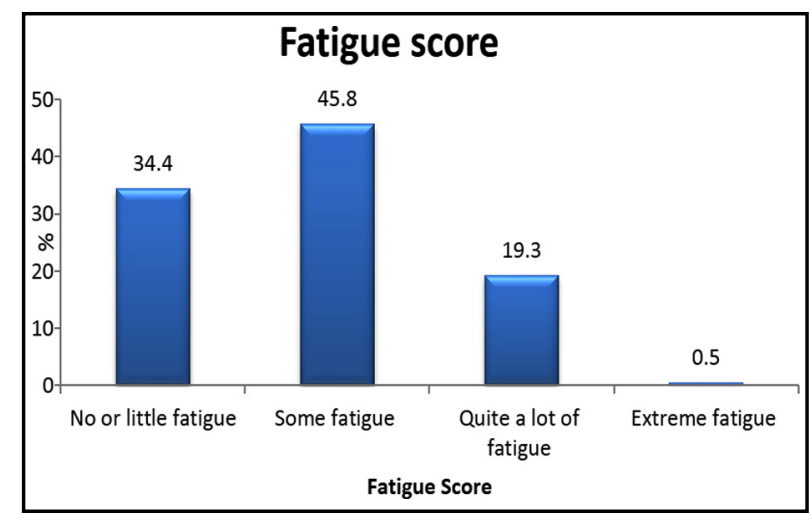

Bar Chart :1 
Abrar Ahmed Wagan et al.

Table-III: Association of Fatigue with Studied Parameters Using Pearson Chi Square test.

\begin{tabular}{|c|c|c|c|c|c|c|c|c|}
\hline \multirow{2}{*}{ Characteristics } & & \multicolumn{2}{|c|}{$\begin{array}{c}\text { No or little fatigue } \\
(n=66)\end{array}$} & \multicolumn{2}{|c|}{$\begin{array}{l}\text { Some fatigue } \\
\quad(n=88)\end{array}$} & \multicolumn{2}{|c|}{$\begin{array}{l}\text { Quite a lot fatigue } \\
\quad(n=37)\end{array}$} & \multirow{2}{*}{$p$-valu } \\
\hline & & $n$ & $\%$ & $n$ & $\%$ & $n$ & $\%$ & \\
\hline \multirow{3}{*}{$\begin{array}{l}\text { Age Group } \\
\text { (years) }\end{array}$} & $<=30$ years & 22 & 33.3 & 12 & 13.6 & 10 & 27.0 & \multirow{3}{*}{$<0.01^{*}$} \\
\hline & 31 - 45 years & 34 & 51.5 & 50 & 56.8 & 8 & 21.6 & \\
\hline & $>45$ years & 10 & 15.2 & 26 & 29.5 & 19 & 51.4 & \\
\hline Sex & Male & 50 & 75.8 & 61 & 69.3 & 26 & 70.3 & 0.74 \\
\hline Marital Status & Married & 52 & 78.8 & 71 & 80.7 & 31 & 83.8 & 0.10 \\
\hline \multirow{5}{*}{ Education } & Uneducated & 15 & 22.7 & 35 & 39.8 & 28 & 75.7 & \multirow{5}{*}{$<0.01^{*}$} \\
\hline & Primary & 6 & 9.1 & 10 & 11.4 & 0 & 0.0 & \\
\hline & Secondary and higher & 27 & 40.9 & 19 & 21.6 & 3 & 8.1 & \\
\hline & Bachelors and beyond & 18 & 27.3 & 24 & 27.3 & 6 & 16.2 & \\
\hline & $<24.9$ :Normal weight & 18 & 27.3 & 15 & 17.0 & 6 & 16.2 & \\
\hline \multirow[t]{2}{*}{ BMI Levels } & 25 - 29.9:over weight & 23 & 34.8 & 29 & 33.0 & 14 & 37.8 & \multirow[t]{2}{*}{0.54} \\
\hline & $>30$ Obese & 25 & 37.9 & 44 & 50.0 & 17 & 45.9 & \\
\hline \multirow[t]{2}{*}{ smoking } & smoker & 53 & 80.3 & 65 & 73.9 & 27 & 73.0 & \multirow[t]{2}{*}{0.70} \\
\hline & Upper & 5 & 7.6 & 6 & 6.8 & 3 & 8.1 & \\
\hline \multirow{3}{*}{ Social Status } & Middle & 29 & 43.9 & 31 & 35.2 & 9 & 24.3 & \multirow{3}{*}{0.11} \\
\hline & Working & 13 & 19.7 & 17 & 19.3 & 2 & 5.4 & \\
\hline & Poor & 19 & 28.8 & 34 & 38.6 & 23 & 62.2 & \\
\hline \multirow[t]{2}{*}{ Hypertension } & Yes & 7 & 10.6 & 16 & 18.2 & 14 & 37.8 & \multirow[t]{2}{*}{$<0.01^{*}$} \\
\hline & $<2.6$ : Remission & 12 & 18.2 & 33 & 37.5 & 19 & 51.4 & \\
\hline \multirow{3}{*}{ DAS-28 } & 2.6-3.2: Low & 5 & 7.6 & 27 & 30.7 & 12 & 32.4 & \multirow{3}{*}{$<0.01^{*}$} \\
\hline & 3.2 - 5.1 : Moderate & 33 & 50.0 & 23 & 26.1 & 5 & 13.5 & \\
\hline & $>5.1$ : High & 16 & 24.2 & 5 & 5.7 & 1 & 2.7 & \\
\hline \multirow{3}{*}{ Exercise level. } & Regular & 19 & 28.8 & 17 & 19.3 & 5 & 13.5 & \multirow{3}{*}{$0.04^{*}$} \\
\hline & Never & 31 & 47.0 & 54 & 61.4 & 30 & 81.1 & \\
\hline & Occasional & 16 & 24.2 & 17 & 19.3 & 2 & 5.4 & \\
\hline $\mathrm{HCV}$ & Positive & 3 & 4.5 & 7 & 8.0 & 10 & 27.0 & $<0.01^{*}$ \\
\hline $\mathrm{Hbs}$ & Positive & 1 & 1.5 & 1 & 1.1 & 3 & 8.1 & 0.13 \\
\hline
\end{tabular}

${ }^{*} \mathrm{p}<0.05$ was considered significant using Pearson Chi Square test.

increases in fatigue scores on average when SBP, DBP kept constant and model adjusted for age and BMI. Table-V.

\section{DISCUSSION}

Fatigue in Rheumatoid arthritis is a common complaint which exerts immense burden over the person's life, impairs the quality of living and incur huge financial losses. Abdel Moneim $\mathrm{H}$. Helal et $\mathrm{al}^{11}$ in case control study found that fatigue is more prevalent in RA patients who had raised serum levels of interleukin-6, independent
Table-IV: Correlation Analysis of Fatigue Scores.

\begin{tabular}{llll}
\hline Parameters & $R$-value & $R$-square (\%) & $p$-value \\
\hline Duration of disease & -0.052 & 0.27 & 0.475 \\
BMI $(\mathrm{kg} / \mathrm{m} 2)$ & -0.151 & 2.28 & $0.036^{*}$ \\
SBP & -0.197 & 3.88 & $0.006^{*}$ \\
DBP & -0.148 & 2.19 & $0.04^{*}$ \\
FBS & -0.122 & 1.49 & 0.091 \\
Disease Activity & 0.426 & 18.15 & $<0.01^{*}$ \\
score & & & \\
\hline
\end{tabular}

${ }^{*} \mathrm{p}<0.05$ was considered significant. 
Fatigue assessment in Pakistani cohort with RA

Table-V: Effect of Studied Parameters on Fatigue Score.

\begin{tabular}{|c|c|c|c|c|c|c|}
\hline \multirow{2}{*}{ Independent Parameters } & \multicolumn{2}{|c|}{ Beta Coefficients } & \multirow{2}{*}{ t-value } & \multirow{2}{*}{ p-value } & \multicolumn{2}{|c|}{$95.0 \%$ Confidence Interval for $B$} \\
\hline & $B$ & S.E & & & Lower Bound & Upper Bound \\
\hline SBP & -0.03 & 0.05 & -.619 & 0.53 & -0.13 & 0.07 \\
\hline DBP & 0.03 & 0.09 & .395 & 0.69 & -0.15 & 0.22 \\
\hline Disease Activity score & 2.71 & 0.46 & 5.894 & $<0.01^{*}$ & 1.80 & 3.61 \\
\hline
\end{tabular}

Dependent Variable: Fatigue score: Model were adjusted for Age and BMI , ${ }^{*} \mathrm{P}<0.05$ was considered significant.

of disease duration and activity. In our study results we found there was direct relationship between disease activity and fatigue score, Dhir et al also reported same it is significantly associated with high DAS28 scores. ${ }^{12}$

Cécile L. Overman et al in his international sample study described the frequency of fatigue in various rheumatic diseases and reported 41 to $57 \%$ of patients with rheumatoid arthritis had severe fatigue and in our study, we found frequency of $63.2 \% .^{13}$

Fatigue taken as important extra-articular manifestation of RA, related to disease activity, there are multiple causes for it, including disability, sound mental health, social support and wellbeing, it has been cause of various deleterious effects in a patient's life like: leads to role limitations in (36-44\%), physical and social issues in (52-57\%), reason of mental health effects in (64\%), and most importantly being the prime reason for perception of worsening of health (51\%). ${ }^{14}$

Fatigue incurs some harmful effects on persons daily living like: activity impairment (OR 1.52; $95 \%$ CI: $0.79,2.26$ ) and work productivity loss (OR 4.16; 95\% CI: 2.47, 5.85). ${ }^{15}$ In patients where RA is difficult to control labeled as (difficult to treat) fatigue might the biggest contributor, making treatment plans more challenging and ultimately more health care load. ${ }^{16}$ Fatigue causes problems in assessment of disease activity, considered as the main factor which affects the components disease activity scales like self-assessment of global impact of the disease (patient global assessment), due to it persistence patients might not get the benefits of better disease control despite of disease remission. ${ }^{17,18}$

We have assessed the severity of fatigue in established RA patients, its socioeconomic determinants and looked into the impact of anti hcv and Hbs Ag status over fatigue, prior to this no study has seen towards this side as these chronic hepatitis is very common in south Asian countries.
In current study the mean fatigue scores was $(34.94 \pm 8.88)$ units, Trine $\mathrm{P}$ et $\mathrm{al}^{8}$ also found near similar results with mean score of $(34.86 \pm 11.04)$ but our study population was much younger.

Its pathophysiology is linked to disease activity, persistent pain, sleep deprivation, mood disturbances, other diseases, high inflammatory markers, elevated cytokines, with these a person feel tired or even exhausted similarly to prodrome of an infection. ${ }^{19}$ Fatigue has been linked to conventional DMARDs use, specially methotrexate and sulfasalazine, this may contribute to non-adherence to their use, so change in mode of administration and dosing regimen may help..$^{20,21}$ Fatigue has severe financial impact leading to very high clinical care costs, increasing consultations, key determinant of sickness, absence and loss of employment, despite of its perceived importance and increased research activity, our understanding for prognostic factors of poor fatigue outcomes is lacking, ultimately poorly managed. ${ }^{22}$

Curbing fatigue is possible, by multidimensional approach (non-pharmacologic and pharmacologic) measures, like exercise, cognitive behavioral therapy ,timely and effective use of conventional and biological dmards especially IL-6 blocker (Tocizilumab) and newer medications called conventional synthetic dmards Janus kinase (JAK) inhibitors (tofacinitab, baricinitab), in active, early RA, methotrexate naive, methotrexate and biologics inadequate responders shown major improvements, also treatment of anemia, Vit D and Omega 3 fatty acids supplementation may help. ${ }^{19}$

\section{CONCLUSION}

Fatigue in RA is complex entity, over all it has a negative impact on person's wellbeing. Fatigue needs to be addressed and assessed at least twice a year with validated tool. Its management in terms of early diagnosis and treatment is very important as this may lead noncompliance of some very basic and essential medications required for control. This 
may be always considered in those who couldn't reach treat to target goals.

Limitations of the Study: This is a cross sectional study, with small sample size, results can't be generalized, more longitudinal studies are required to know the dynamics of fatigue, frequency and management, while this is the first study of its kind done on local population, used a fatigue assessment tool which is translated in local language and easy to understand.

\section{Conflict of interests: None.}

Funding: None.

Acknowledgement: $\mathrm{Mr}$ Adnan (Phd fellow) in Statistics at University of Karachi Pakistan for his help in data analysis.

\section{REFERENCES}

1. Milman N, Karsh J, Booth RA. Correlation of a multicytokine panel with clinical disease activity in patients with rheumatoid arthritis. Clin Biochem 2010;43:1309-1314.

2. Bax M, van Heemst J, Huizinga TW, Toes RE. Genetics of rheumatoid arthritis: what have we learned? Immunogenetics. 2011;63:459-466.

3. Emonts M, Hazes MJ, Houwing-Duistermaat JJ, De Jongh CE, De Vogel L, Han HK, et al. Polymorphisms in genes controlling inflammation and tissue repair in rheumatoid arthritis: a case control study. BMC Med Genet 2011;12:36.

4. Leonardo D, Sandor B, Talita S, Luciana M, Wagner M, Licia M. Measuring fatigue with multiple instruments in a Brazilian cohort of early rheumatoid arthritis patients. rev b r a s r e u m a t o l. 2017;57(5):431-437. doi: 10.1016/j. rbre.2017.05.004

5. Van Steenbergen HW, Tsonaka R, Huizinga TWJ, et al. Fatigue in rheumatoid arthritis; A persistent problem: a large longitudinal study. RMD Open 2015;1:e00041. doi: 10.1136/rmdopen-2014-000041

6. Mota H, Laurindo M, Santos L. Demographic and clinical characteristics of a cohort of patients with early rheumatoid arthritis. Rev Bras Reumatol. 2010;50:235-248.

7. Almeida M, Almeida M, Bertolo B. Demographic and clinical features of patients with rheumatoid arthritis in Piauí, Brazil - evaluation of 98 patients. Rev Bras Reumatol. 2014;54:360-5.9

8. Trine P, Lise H, Sandra S, Henrik J, Bente E. Severity of fatigue in people with rheumatoid arthritis, psoriatic arthritis and spondyloarthritis - Results of a cross-sectional study. PLoS ONE. 14(6):e0218831. doi: 10.1371/journal pone. 0218831

9. Sevinç S, Zeynep O, Fatigue in rheumatic diseases, Eur J Rheumatol. 2015;3:109-113. doi: 10.5152/ eurjrheum.2015.0029.

10. Sarah H, Emma D, Celia A, Measures of Fatigue. Arth Care Res. 2011;63(11):S263-S286. doi: 10.1002/acr.20579
11. Abdel H, Enas S, Marwa H, Doaa H, Riham M. Fatigue in rheumatoid arthritis and its relation to interleukin-6 serum level. The Egyptian Rheumatologist. 2012;34:153-157. doi: 10.1016/j.ejr.2012.08.004.

12. Dhir V, Lawrence A, Aggarwal A, Misra R. Fibromyalgia is common and adversely affects pain and fatigue perception in North Indian patients with rheumatoid arthritis. J Rheumatol. 2009;36:2443-2448.

13. Cecile $O$, Marianne $K$, Jose S, Rinie G, The frequency of severe fatigue in rheumatic diseases: An international study. Clin Rheumatol. 2016;35:409-415. doi: 10.1007/s10067-0153035-6

14. Eduardo S, Catia D, Jose' S, Ricardo F, The impact of fatigue in rheumatoid arthritis and the challenges of its assessment. Rheumatology 2019;58:v3v9 doi: 10.1093/rheumatology/ kez351

15. Katie D, Laraine A, Maria D, Annie B, Piotr S, Neil B. Fatigue independently predicts different work disability dimensions in etanercept- treated rheumatoid arthritis and ankylosing spondylitis patients. Arthritis Res Therapy. 2018;20:96. doi: 10.1186/s13075-018-1598-8

16. Nadia R, Maria H, Marlies G, Johannes J, Paco W, Desiree van der $\mathrm{H}$, et al. Characteristics of difficult-to-treat rheumatoid arthritis: results of an international survey. Ann Rheum Dis. 2018;77:1705. doi: 10.1136/annrheumdis-2018-213687

17. Lilian T, Martina S, Sarah H, Bev D, Caroline F, Laure G, et al. The patient perspective on absence of disease activity in rheumatoid arthritis: a survey to identify key domains of patient-perceived remission. Ann Rheum Dis. 2017;76:85561. doi: 10.1136/annrheumdis-2016-209835

18. Ricardo F, Maxime D, John K, Catia D, Maarten W, Martin $S$, et al . Drivers of patient global assessment in patients with rheumatoid arthritis who are close to remission: an analysis of 1588 patients. Rheumatology (Oxford). 2017;56:15738. doi: 10.1093/rheumatology/kex211

19. Pope JE. Management of Fatigue in Rheumatoid Arthritis. RMD Open 2020;6:e001084. doi: 10.1136/ rmdopen-2019-001084

20. Ingrid D, Susanne $\mathrm{P}$, Birgitta $\mathrm{N}$, Alyssa BD, Christina $\mathrm{O}$, Associations between fatigue and physical capacity in people moderately affected by rheumatoid arthritis. Rheumatol Int. 2018;38:2147-2155. doi: 10.1007/s00296-0184140-z

21. Holly H, Kimme H, James A, James B, Jamie S, Anne B. et al. The predictors of and reasons for non-adherence in an observational cohort of patients with rheumatoid arthritis commencing methotrexate. Rheumatology. 2020;59:213223. doi: $10.1093 /$ rheumatology/kez274

22. Katie D, Neil B, Predictors of fatigue in rheumatoid arthritis. Rheumatology. 2019;58:v29v34. doi: 10.1093/ rheumatology/kez346

\section{Authors Contribution:}

AAW: Design, drafting, Data acquisition data analysis, data interpretation, final approval.

AR, AB, and TZ: Data acquisition, data analysis, interpretation, drafting, final approval. 